\title{
APPLICATION ISSSUES OF THE SEMI-MARKOV RELIABILITY MODEL
}

Jacek Rudnicki, Ph. D.

Gdańsk Univeristy of Technology, Poland

\begin{abstract}
Predicting the reliability of marine internal combustion engines, for instance, is of particular importance, as it makes it possible to predict their future reliability states based on the information on the past states. Correct reliability prediction is a complex process which consists in processing empirical results obtained from operating practice, complemented by analytical considerations. The process of technical state changes of each mechanical device is stochastic and continuous in states and time, hence the need to divide this infinite set of engine states into a finite number of subsets (classes), which can be clearly and permanently identified using the existing diagnosing system. Using the engine piston-crankshaft system as an example, the article presents a proposal for a mathematical model of reliability which, on the one hand, takes into account random nature of phenomena leading to the damage, and at the same time reveals certain application flexibility and the resultant practical usability.
\end{abstract}

Keywords: service speed, shipping lines, preliminary design

\section{INTRODUCTION}

The piston-crankshaft system is functionally one of most important subsystems in the engine, and its importance is additionally increased by the fact that all maintenance activities concerning particular components of this system are connected, as a rule, with serious interference into the engine structure and its long lasting shutdown. Thus the state of the piston-crankshaft system is crucial for the reliability and overall performance of the engine.

During engine operation, its elements are exposed to degradation excitations, which leads to their wear (see: tribological systems of the engine, for instance). This wear, in turn, affects the work process and performance parameters. In the analysed functional system three structural nodes can be named, the technical state of which affects decisively the abovementioned parameters, as well as the general technical state and reliability of the engine. These nodes are: the piston rings-cylinder liner node, the piston-cylinder liner node, and the crosshead, crankshaft and main bearings.

In general, the effect of gradual wear of piston-crankshaft system elements on parameters of the work process can manifest itself in three ways, i.e. as [6]:

- decrease of final parameters of charge compression in the cylinder (pressure and temperature),

- change of conditions of atomisation of the fuel delivered to the cylinder,

- increase of mechanical losses (own resistance) of the engine.
At constant fuel pump setting $\left(\mathrm{h}_{\mathrm{p}}=\right.$ const), the increased charge loss caused by decreased piston tightness in the cylinder leads to the decrease of the excess air number $(\lambda)$. This, in turn, slows down the combustion process, which overlaps the beginning of the decompression stroke and takes place at an increased gas temperature. In the above situation, intensive heat transfer from the wall to the cooling medium and the resultant decrease of the indicated efficiency are observed.

The decrease of the excess air number $(\lambda)$ and the average indicated pressure $\left(\mathrm{p}_{\mathrm{i}}\right)$ is accompanied by the decrease of the mechanical efficiency $\left(\eta_{\mathrm{m}}\right)$, which in turn leads to the decrease of the engine power $\left(\mathrm{N}_{\mathrm{e}}\right)$.

Moreover, if this phenomenon is accompanied by excessive wear of bearings in the crankshaft system, the piston stroke in the compression process becomes shorter due to summing up of the increased bearing clearances. The final result is the increased volume of combustion chamber and decreased cylinder compression ratio $(\varepsilon)$.

Simultaneous action of the charge loss and compression ratio decrease can remarkably affect the indicated efficiency.

The decrease of final compression parameters due to wear of system elements leads to the change of conditions of atomisation and combustion of the fuel delivered to the cylinder. Theoretically, the fuel self-ignition in the cylinder should take place when the combustion temperature becomes equal to the self-ignition temperature. The decrease of the compression pressure and fuel charge density being the result of the lack of piston tightness in the cylinder lead finally to 
the increase of the ignition lag $-\tau$.

The quality of the mixture formation process in the Diesel engine combustion chamber is characterised by, among other parameters, the size of droplets of the fuel atomised in the cylinder and the distribution of these droplets in the cylinder space. The average diameter of the fuel injected to the cylinder depends on, among other factors, the injection pressure and the final compression pressure. The decrease of the compression pressure at the same fuel injection pressure means the increase of the average droplet of fuel delivered to the cylinder. At the same time the temperature of the fuel charge in the combustion chamber decreases, which leads to:

- longer ignition lag $-\tau_{s}$,

- higher pressure build-up rate - $\Delta \mathrm{p} / \Delta a$,

- larger maximal pressure angle $a_{\text {pmax }}$,

- longer combustion process which overlaps the decompression line.

Figure 1 shows a sample illustration of the above phenomenon, recorded during empirical examination of the experimental engine Farymann D10.

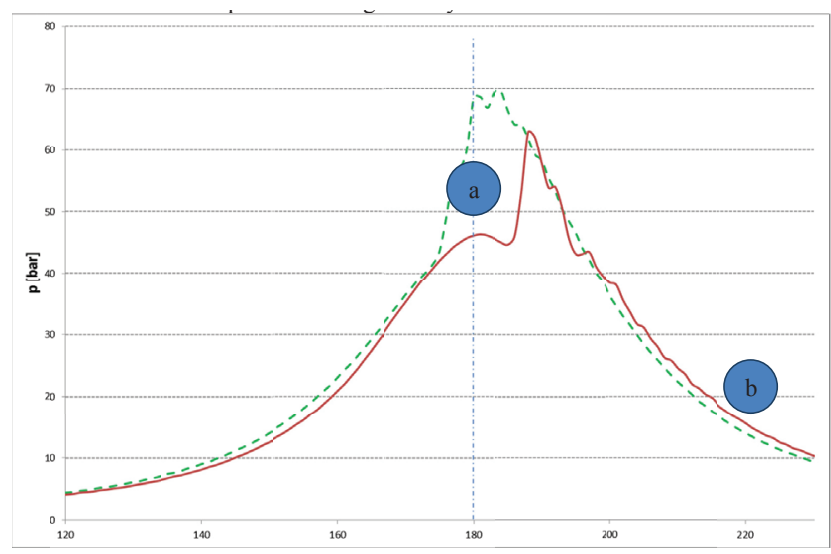

Fig. 1. The effect of increased clearances in the piston-crankshaft system on the combustion process, shown as pressure change in the workspace vs. crankshaft rotation angle: a) correct technical state of the piston-cylinder group; $b$ ) increased charge loss. (source: in-house research)

\section{MODELLING THE PROCESS OF TECHNICAL STATE CHANGES}

Due to various types of excitations, such as high temperature and/or pressure, friction, corrosion, erosion, cavitation, etc., acting on particular structural nodes of the engine during the execution of the working process, and additionally accompanied by the ageing process, structural parameters of the engine are subject to continuous changes.

Since the above process is continuous in time and each set of parameters describes a single technical state of the engine, the number of these sets is obviously infinite.

In terms of applicability of the main ship propulsion engine to the realisation of the target function (reliability state) determined by the state of the piston-crankshaft system, the following subsets (classes) of technical states which need identification can be named:

- $\quad$ state subset $S_{0}$ - state of full operating ability of the system. In this technical state the system can perform all assigned tasks.

- $\quad$ state subset $S_{1}$ - state of partial operating ability of the piston-cylinder group. In this state the system allows the engine to perform tasks at the presence of the existing and worsening limitations resulting, first of all, from tribological wear which dominates in this structural node. Main symptoms which suggest this state of the node include [6]:

- decreased combustion pressure,

- $\quad$ increased exhaust gas temperature resulting from the decrease of the excess air number and the increase of the time of combustion process (shifting the combustion towards the decompression stroke).

- $\quad$ state subset $\mathrm{S}_{2}$ - state of operating inability of the piston-cylinder group. In this state the system makes performing any tasks by the engine impossible, first of all due to:

- inability to reach sufficiently high temperature of the fuel charge at the end of compression stroke, mainly due to remarkable loss of tightness (caused by burning of the piston bottom, for instance),

- highly likely possibilities of extensive engine damage resulting from the possible use of elements of the piston-cylinder group in the technical state belonging to this class of states.

- $\quad$ state subset $S_{3}$ - state of partial operating ability of system bearings. These bearings are exposed to cyclic loads and, consequently, are subject to relatively fast tribological and erosion wear, having most often the form of [3]:

- abrasive and adhesive wear of I and II type intensified by local exceeding of the bearing capacity of the half-shell due to, for instance, excessive pressure and insufficient thickness of the oil film,

- friction-corrosion wear (fretting) caused by cyclic loads in the environment of harmful lubricating oil components,

- cavitation erosion caused by fast radial movements of the journal with respect to the half-shell or by changes of oil flow direction,

- $\quad$ hydro erosion caused by excessively large oil flow velocities, due to, for instance, very high oil pressure.

The above named wear processes affect negatively the lubrication process due to unfavourable changes of the hydraulic pressure distribution and the shape of the oil wedge in bearings, which after some time of engine operation leads to remarkable increase of friction moment in bearings and, in this class of states, to the increase of mechanical loss in the entire engine. - $\quad$ state subset $\mathrm{S}_{4}$ - state of operating inability of system bearings. These processes can lead to the damage of bearings. However, beside damages directly caused by the above wear processes, the bearings are also exposed to: - fatigue wear caused by: exceeding the fatigue 
strength limit in higher temperature, excessive bearing clearance, faulty connection of the bearing alloy with the foundation, and/or journal vibrations caused by shaft imbalance or incorrect bearing assembly,

- local overheating of the half-shell and melting out of the bearing alloy caused by local decrease of oil film thickness, or insufficient lubrication with simultaneous bearing overloading.

- $\quad$ state subset $S_{5}$ - state of partial operating ability of both the piston-cylinder group, and the bearings.

The elements of the set of the above defined technical state subsets $\mathrm{S}=\{\mathrm{s} ; \mathrm{i}=1,2,3,4,5\}$ are the values of the process $\{\mathrm{W}(\mathrm{t})$ : $t \geq 0\}$, which is composed of successive states $s_{i} \in S$, being in causal relations.

Based on [2], such a model can have the form of the stochastic semi-Markov process with a discrete set and continuous duration time of the identified states.

For the analysed case (the above set of state classes), the graph of state changes of the process $\{\mathrm{W}(\mathrm{t}): \mathrm{t} \in \mathrm{T}\}$ can be presented in the following way [4][5]:

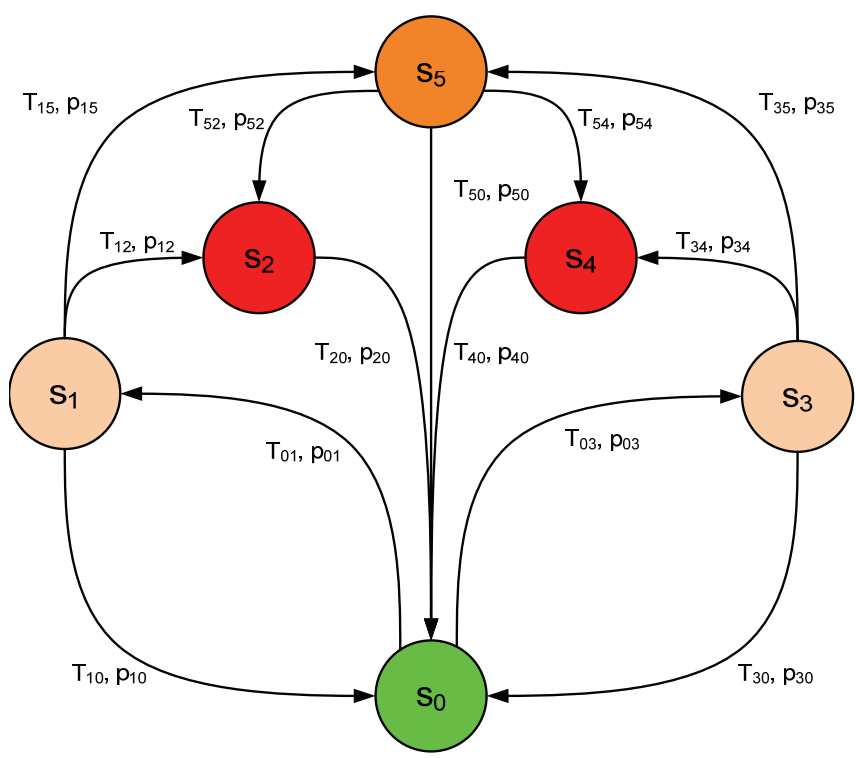

Fig. 2. Graph of state changes - passages of the process $\{W(t): t \in T\}$. $s_{0}$ - subset of states $S_{0}$ : full operating ability of the system, $s_{1}-$ subset of states $S_{1}$ : partial operating ability of the piston-cylinder group, $s_{2}-$ subset of states $S_{2}$ : operating inability of the piston-cylinder group, $s_{3}-$ subset of states $S_{3}$ : partial operating ability of system bearings, $s_{4}-$ subset of states $S_{4}$ : operating inability of system bearings, $s_{5}$ - subset of states $S_{5}$ : partial operating ability of both the piston-cylinder group and system bearings; $T$ - random variable describing the duration time of state s provided that the process passes to the state $s_{k}(i, k=0,1,2,3,4,5 i \neq k) ; p_{i k}$ - probability of process passing from state $s_{i}$ to state $s_{k}(i, k=0,1,2,3,4,5 i \neq k)$;

As results from the graph, the functional matrix of the analysed process has the following form:

$$
Q(t)=\left[\begin{array}{cccccc}
0 & Q_{01}(t) & 0 & Q_{03}(t) & 0 & 0 \\
Q_{10}(t) & 0 & Q_{12}(t) & 0 & 0 & Q_{15}(t) \\
Q_{20}(t) & 0 & 0 & 0 & 0 & 0 \\
Q_{30}(t) & 0 & 0 & 0 & Q_{34}(t) & Q_{35}(t) \\
Q_{40}(t) & 0 & 0 & 0 & 0 & 0 \\
Q_{50}(t) & 0 & Q_{52}(t) & 0 & Q_{54}(t) & 0
\end{array}\right]
$$

while the initial distribution of the process $\{\mathrm{W}(\mathrm{t}): \mathrm{t} \geq 0\}$ can be given as follows:

1. for engines at the initial time of operation:

$$
\begin{aligned}
& \mathrm{p}_{1}=\mathrm{P}\left\{\mathrm{W}(0)=\mathrm{s}_{0}\right\}=1, \\
& \mathrm{p}_{\mathrm{i}}=\mathrm{P}\left\{\mathrm{W}(0)=\mathrm{s}_{\mathrm{i}}\right\}=0 \text { for } \mathrm{i}=1, \ldots, 5 ;
\end{aligned}
$$

as engines at the initial time of operation $(t=0)$ should be in state $s_{1}$.

2. for currently operated engines:

$$
\begin{aligned}
& \mathrm{p}_{0}=\mathrm{P}\left\{\mathrm{W}(0)=\mathrm{s}_{0}\right\}=k, \\
& \mathrm{p}_{1}=\mathrm{P}\left\{\mathrm{W}(0)=\mathrm{s}_{1}\right\}=m, \\
& \mathrm{p}_{3}=\mathrm{P}\left\{\mathrm{W}(0)=\mathrm{s}_{3}\right\}=n, \\
& \mathrm{p}_{5}=\mathrm{P}\left\{\mathrm{W}(0)=\mathrm{s}_{5}\right\}=r, \\
& k+m+n+r=1 ; \quad k, m, n, r \geq 0 \\
& \mathrm{p}_{\mathrm{i}}=\mathrm{P}\left\{\mathrm{W}(0)=\mathrm{s}_{\mathrm{i}}\right\}=0 \text { for } \mathrm{i}=2 \cup 4 ;
\end{aligned}
$$

as engines at the current time of operation $t>0$ (except those excluded from operation) can be in states $\mathrm{s}_{0}$, or $\mathrm{s}_{1}$, or $\mathrm{s}_{3}$, or $\mathrm{s}_{5}$ with the probabilities $k, m, n, r$, respectively.

\section{MARKOV PROCESS AS ALTERNATIVE FOR THE SEMI-MARKOV MODEL}

Numerical values of the above characteristics can be calculated provided that relevant statistics from operational tests of engines have been collected.

This way, practical applicability of the presented mathematical model mainly depends on the access to reliable results of operational tests which could be used for model verification. Since obtaining results of tests performed on sea going vessels is extremely time consuming and needs huge effort (also financial), such results are rare and hardly available.

In this situation, the problem arises how to verify the developed mathematical models of the process of technical state changes.

A solution here could be to replace the semi-Markov process in the presented model by the Markov process - $\left\{\mathrm{W}^{\prime}(\mathrm{t}): \mathrm{t} \in \mathrm{T}\right\}$.

A basic advantage of the use of exponential distributions is a possibility to obtain simple relations defining the distribution of the analysed process based on "residual" and incomplete results of operational tests, complemented by the data taken from technical and repair documentation.

Calculating the probabilities of staying of the marine internal combustion engine (or any of its systems) in particular states requires the Kolmogorov equations for the adopted model of technical state changes to be formulated. For this purpose, the probabilities of changes $\mathrm{p}_{\mathrm{ij}}$ (Fig. 2), are replaced by the intensities of changes $-\lambda_{i j}(i, j=1,2, \ldots, I ; i \neq j)$ having the following interpretation [1]:

$$
\lambda_{i j}(t)=\lim _{\tau \rightarrow 0} \frac{\mathrm{P} \mathrm{W}(\mathrm{t}+\tau)=\mathrm{s}_{\mathrm{j}} / W(t)=s_{i}}{\tau}
$$


In practice, a reliable and convenient representative of this quantity can be another quantity assessed from tests or calculated based on technical engine documentation and producer's recommendations. This new quantity is defined as:

$$
\lambda_{i j}=\frac{1}{E\left(T_{i j}\right)} \cong \frac{1}{\bar{T}_{i j}}, \quad(i, j=12, \ldots, I ; i \neq j)
$$

where:

$\mathrm{E}\left(\mathrm{T}_{\mathrm{ij}}\right)$ - expected value of the random variable describing the duration time of state $s_{i}$ provided that the next state is $s_{j}$,

$\bar{T}_{i j}$ - average time of staying of the engine (system) in state $s_{i}$ provided that the next state is $s_{j}$, evaluated from tests or/and technical engine documentation and producer's recommendations.

Taking into account relations $(2,3)$, a modified graph of state changes of the new process $\left\{W^{\prime}(t): t \in T\right\}$ can be presented for the analysed case as [ 4][ 5]:

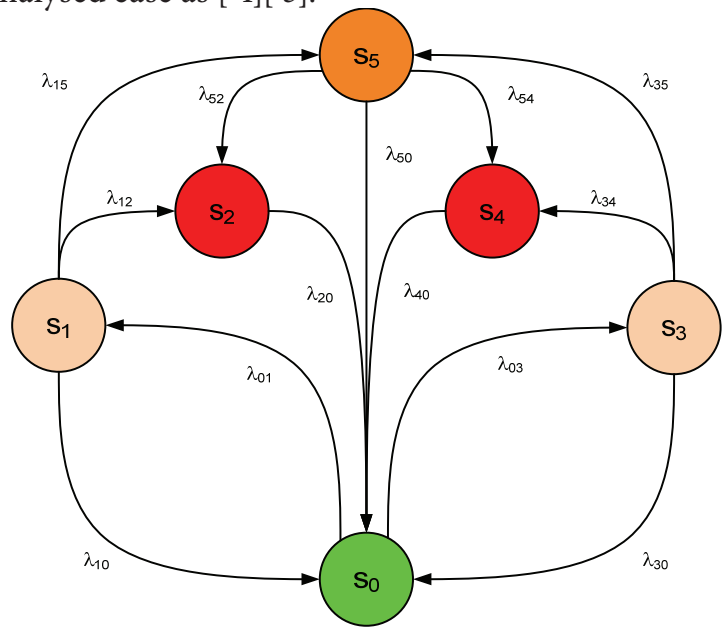

Fig. 3. Graph of state changes - passages of the process $\left\{W^{\prime}(t): t \in T\right\}$. $s_{0}-$ subset of states $S_{0}$ : full operating ability of the system, $s_{1}-$ subset of states $S_{l}$ : partial operating ability of the piston-cylinder group, $s_{2}-$ subset of states $S_{2}$ : operating inability of the piston-cylinder group, $s_{3}$ - subset of states $S_{3}$ : partial operating ability of system bearings, $S_{4}-$ subset of states

$S_{4}$ : operating inability of system bearings, $s_{5}$ - subset of states $S_{5}$ : partial operating ability of both piston-cylinder group and system bearings; $\lambda_{i k}$ - intensity of passing from state $s_{i}$ provided that the next state is $s_{k}(i, k=0,1,2,3,4,5 i \neq k)$;

Taking into account the graph of process state changes $\left\{\mathrm{W}^{\prime}(\mathrm{t}): \mathrm{t} \in \mathrm{T}\right\}$ and its initial distribution, which, after taking into account process assumptions $\{\mathrm{W}(\mathrm{t}): \mathrm{t} \geq 0\}$ is described in the identical way as for the semi-Markov process, the system of Kolmogorov equations having the general form [1]:

$$
\frac{d P_{i}(t)}{d t}=-\left(\sum_{j} \lambda_{i j}\right) \cdot P_{i}(t)+\sum_{j}\left(\lambda_{j i} \cdot P_{j}(t)\right) \quad i \neq j
$$

will have the following exact form for the analysed case:

$$
\left.\begin{array}{c}
\frac{d P_{0}(t)}{d t}=-\left(\lambda_{01}+\lambda_{03}\right) \cdot P_{0}(t)+\lambda_{10} \cdot P_{1}(t)+\lambda_{20} \cdot P_{2}(t)+ \\
+\lambda_{30} \cdot P_{3}(t)+\lambda_{40} \cdot P_{4}(t)+\lambda_{50} \cdot P_{5}(t) \\
\frac{d P_{1}(t)}{d t}=-\left(\lambda_{10}+\lambda_{12}+\lambda_{15}\right) \cdot P_{1}(t)+\lambda_{01} \cdot P_{0}(t) \\
\frac{d P_{2}(t)}{d t}=-\lambda_{20} \cdot P_{2}(t)+\lambda_{12} \cdot P_{1}(t)+\lambda_{52} \cdot P_{5}(t) \\
\frac{d P_{3}(t)}{d t}=-\left(\lambda_{30}+\lambda_{34}+\lambda_{35}\right) \cdot P_{3}(t)+\lambda_{03} \cdot P_{0}(t) \\
\frac{d P_{4}(t)}{d t}=-\lambda_{40} \cdot P_{4}(t)+\lambda_{34} \cdot P_{3}(t)+\lambda_{54} \cdot P_{5}(t) \\
\frac{d P_{5}(t)}{d t}=-\left(\lambda_{50}+\lambda_{52}+\lambda_{54}\right) \cdot P_{5}(t)+\lambda_{15} \cdot P_{1}(t)+\lambda_{35} \cdot P_{3}(t)
\end{array}\right\}
$$

The above system of differential equations can be transformed, using the Laplace transform and the defined initial distribution of the process, to the system of linear equations in the transform domain which for two initial distribution variants have the following forms:

Solving the above equation system and finding the inverse Laplace transform gives the required distribution $\mathrm{P}_{\mathrm{i}}(\mathrm{t})$.

1.

$$
\left.\begin{array}{c}
s \cdot P_{0}(s)-1=-\left(\lambda_{01}+\lambda_{03}\right) \cdot P_{0}(s)+\lambda_{10} \cdot P_{1}(s)+\lambda_{20} \cdot P_{2}(s)+ \\
+\lambda_{30} \cdot P_{3}(s)+\lambda_{40} \cdot P_{4}(s)+\lambda_{50} \cdot P_{5}(s) \\
s \cdot P_{1}(s)=-\left(\lambda_{10}+\lambda_{12}+\lambda_{15}\right) \cdot P_{1}(s)+\lambda_{01} \cdot P_{0}(s) \\
s \cdot P_{2}(s)=-\lambda_{20} \cdot P_{2}(s)+\lambda_{12} \cdot P_{1}(s)+\lambda_{52} \cdot P_{5}(s) \\
s \cdot P_{3}(s)=-\left(\lambda_{30}+\lambda_{34}+\lambda_{35}\right) \cdot P_{3}(s)+\lambda_{03} \cdot P_{0}(s) \\
s \cdot P_{4}(s)=-\lambda_{40} \cdot P_{4}(s)+\lambda_{34} \cdot P_{3}(s)+\lambda_{54} \cdot P_{5}(s) \\
s \cdot P_{5}(s)=-\left(\lambda_{50}+\lambda_{52}+\lambda_{54}\right) \cdot P_{5}(s)+\lambda_{15} \cdot P_{1}(s)+\lambda_{35} \cdot P_{3}(s)
\end{array}\right\}
$$

2.

$$
\left.\begin{array}{c}
s \cdot P_{0}(s)-k=-\left(\lambda_{01}+\lambda_{03}\right) \cdot P_{0}(s)+\lambda_{10} \cdot P_{1}(s)+\lambda_{20} \cdot P_{2}(s)+ \\
+\lambda_{30} \cdot P_{3}(s)+\lambda_{40} \cdot P_{4}(s)+\lambda_{50} \cdot P_{5}(s) \\
s \cdot P_{1}(s)-m=-\left(\lambda_{10}+\lambda_{12}+\lambda_{15}\right) \cdot P_{1}(s)+\lambda_{01} \cdot P_{0}(s) \\
s \cdot P_{2}(s)=-\lambda_{20} \cdot P_{2}(s)+\lambda_{12} \cdot P_{1}(s)+\lambda_{52} \cdot P_{5}(s) \\
s \cdot P_{3}(s)-n=-\left(\lambda_{30}+\lambda_{34}+\lambda_{35}\right) \cdot P_{3}(s)+\lambda_{03} \cdot P_{0}(s) \\
s \cdot P_{4}(s)=-\lambda_{40} \cdot P_{4}(s)+\lambda_{34} \cdot P_{3}(s)+\lambda_{54} \cdot P_{5}(s) \\
s \cdot P_{5}(s)-r=-\left(\lambda_{50}+\lambda_{52}+\lambda_{54}\right) \cdot P_{5}(s)+\lambda_{15} \cdot P_{1}(s)+\lambda_{35} \cdot P_{3}(s)
\end{array}\right\}
$$

\section{APPLICATION OF THE RELIABILITY MODEL}

To use successfully the above model we need the values of $\lambda_{i j}$. Finding these values is generally very difficult, as it requires long-lasting operational tests. A way which can be 
considered an approximation of the unknown values of $\lambda_{\mathrm{ij}}$ is their assessment based on technical engine documentation, the part concerning periodic inspections.

The engine producer requires such inspections (in this case relating to elements of the piston-crankshaft system) based on the gained experience, therefore we may assume it highly likely that the time intervals between these inspections correspond to the average times of staying in the state of operating and technical ability.

Sample data concerning elements of the piston-crankshaft system for two different engines have been collected in Table 1.

Table 1. Time intervals between inspections of elements of piston-crankshaft systems of marine engines [8], [9]

\begin{tabular}{|c|c|c|c|}
\hline \multirow{2}{*}{ No. } & \multirow{2}{*}{ Scope of inspection } & $\begin{array}{c}\text { Engine } \\
\text { Wartsila } \\
\text { RTA-96C }\end{array}$ & $\begin{array}{c}\text { Engine } \\
\text { MAN B\&W } \\
\text { L32/40 }\end{array}$ \\
\hline & & \multicolumn{2}{|c|}{$\begin{array}{l}\text { Operating time in }[\mathrm{h}] \text {, acc. to } \\
\text { producer: }\end{array}$} \\
\hline 1. & $\begin{array}{l}\text { Dismantling, verification } \\
\text { of technical state of all } \\
\text { pistons. }\end{array}$ & 14000 & 6000 \\
\hline 2. & Replacing piston rings & 20000 & 12000 \\
\hline 3. & $\begin{array}{l}\text { Dismantling, verification } \\
\text { of technical state of one } \\
\text { randomly selected bush } \\
\text { in crankshaft bearings } \\
\text { and one in and main } \\
\text { bearings }\end{array}$ & 8000 & 6000 \\
\hline 4. & $\begin{array}{l}\text { Replacement of all bushes } \\
\text { in crankshaft and main } \\
\text { bearings. }\end{array}$ & 60000 & 36000 \\
\hline
\end{tabular}

Based on the data in Table 1 and making use of relations $(2,3)$ we can determine the first approximation of $\lambda_{\mathrm{ik}}$ for the analysed engines (with no access to the results of reliability tests) in the following way:

- the intensity of passing to the state of partial technical ability of the examined system as the inverse of the average time of staying in the state of operating ability defined by the producer as the time interval between successive planned inspections the scope of which is defined as verification of the randomly selected system (element);

- the intensity of passing to the state of technical inability of the examined system as the inverse of the average time of staying in the state of operating ability defined by the producer as the time interval between successive planned inspections the scope of which is defined as unconditional verification of all systems (elements).

For these assumptions, the collected values of $\lambda_{\mathrm{ik}}$ are given in Table 2.

Table 2. Intensity of changes $\lambda_{i k}$ of the process $\left\{W^{\prime}(t): t \in T\right\}$

\begin{tabular}{|c|c|c|c|}
\hline & $\begin{array}{l}\lambda_{\text {ik }}-\text { intensity of } \\
\text { passing from state }\end{array}$ & $\begin{array}{c}\text { Engine } \\
\text { Wartsila } \\
\text { RTA-96C }\end{array}$ & $\begin{array}{l}\text { Engine MAN } \\
\text { B\&W L32/40 }\end{array}$ \\
\hline INo. & $\begin{array}{l}\text { the next state is } s_{k} \\
(i, k=0,1,2,3,4, \\
5 i \neq k)\end{array}$ & \multicolumn{2}{|c|}{$\left[\mathrm{h}^{-1}\right]$} \\
\hline 1. & $\lambda_{01}$ & $7,14 \times 10^{-5}$ & $1,66 \times 10^{-4}$ \\
\hline 2. & $\lambda_{03}$ & $1,25 \times 10^{-4}$ & $1,66 \times 10^{-4}$ \\
\hline 3. & $\lambda_{10}$ & 0,028571 & 0,042 \\
\hline 4. & $\lambda_{12}$ & $1,66 \times 10^{-4}$ & $1,66 \times 10^{-4}$ \\
\hline 5. & $\lambda_{15}$ & $1,25 \times 10^{-4}$ & $1,66 \times 10^{-4}$ \\
\hline 6. & $\lambda_{20}$ & 0,125 & 0,21 \\
\hline 7. & $\lambda_{30}$ & 0,028571 & 0,042 \\
\hline 8. & $\lambda_{34}$ & $1,92 \times 10^{-5}$ & $3,33 \times 10^{-5}$ \\
\hline 9. & $\lambda_{35}$ & $7,14 \times 10^{-5}$ & $1,66 \times 10^{-4}$ \\
\hline 10. & $\lambda_{40}$ & 0,125 & 0,21 \\
\hline 11. & $\lambda_{50}$ & 0,28571 & 0,42 \\
\hline 12. & $\lambda_{52}$ & $1,66 \times 10^{-4}$ & $1,66 \times 10^{-4}$ \\
\hline 13. & $\lambda_{54}$ & $1,92 \times 10^{-5}$ & $3,33 \times 10^{-5}$ \\
\hline
\end{tabular}

Fig. 4 -6 show the calculated current distribution for the different initial distributions. 
a)

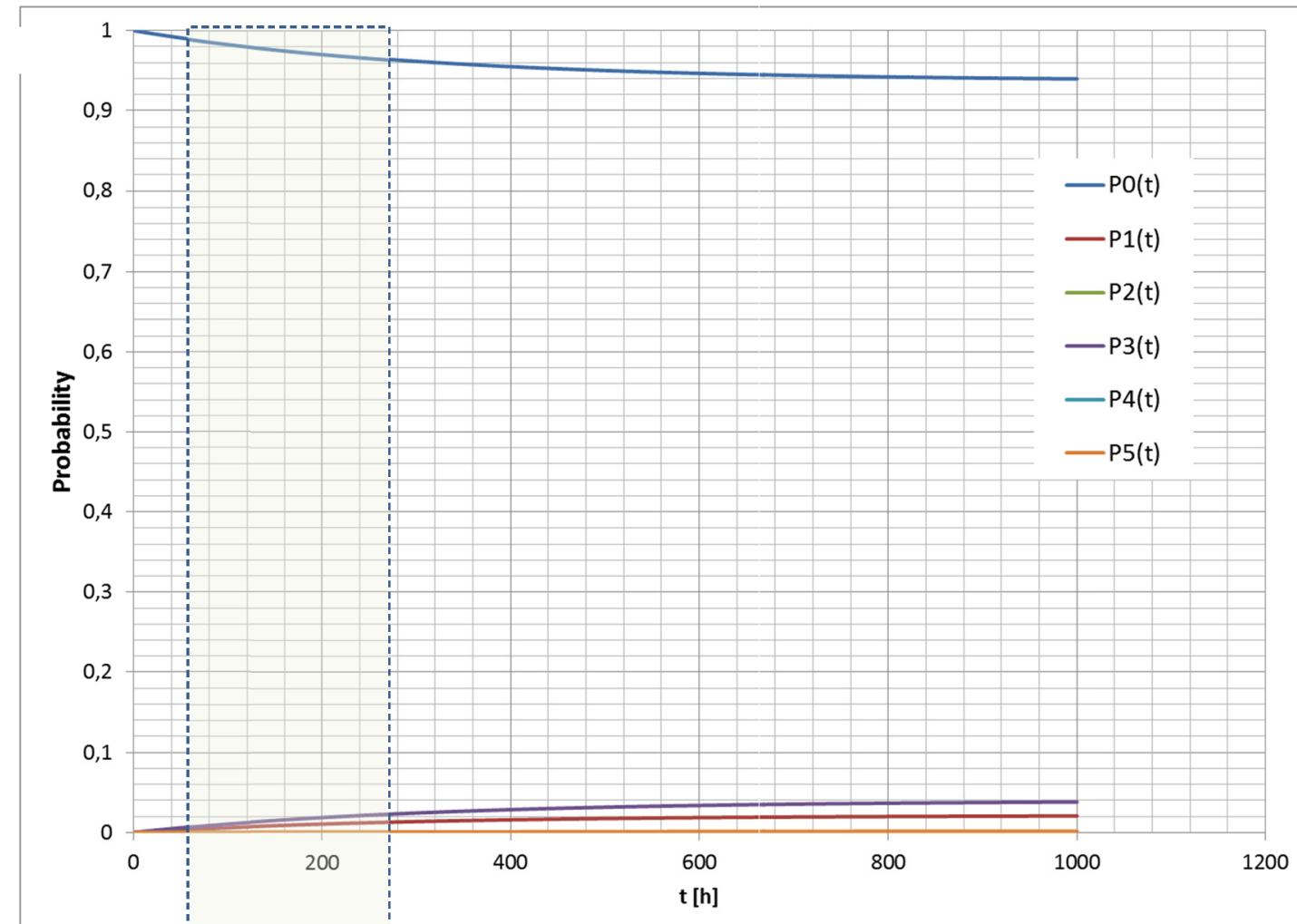

b)

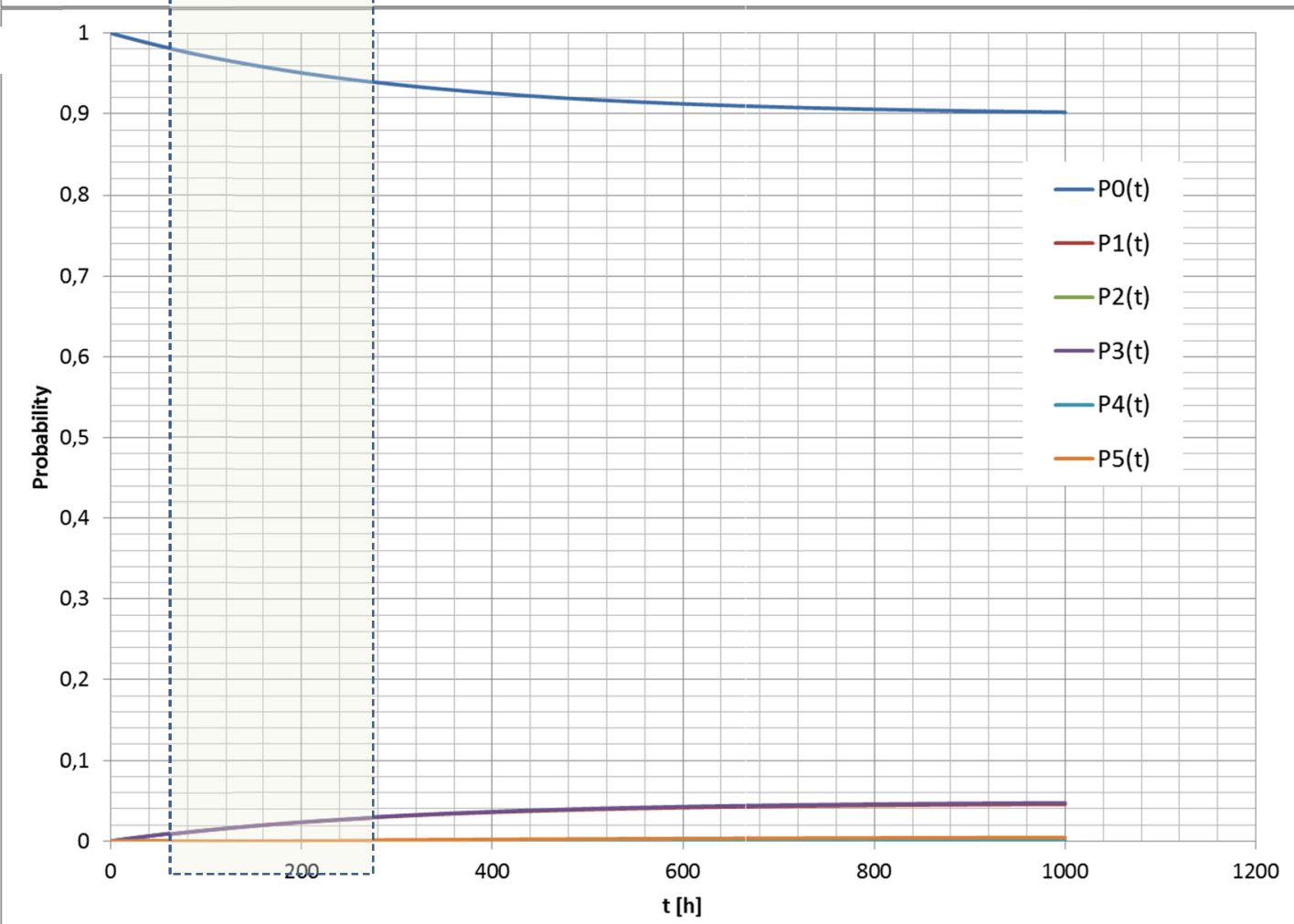

Fig. 4. The calculated current distribution for the initial distribution $p_{0}=P\left\{W^{\prime}(0)=s_{0}\right\}=1, p_{i}=P\left\{W^{\prime}(0)=s_{j}\right\}=0$ for $96 C, b)$ engine MAN B\&W L32/40 


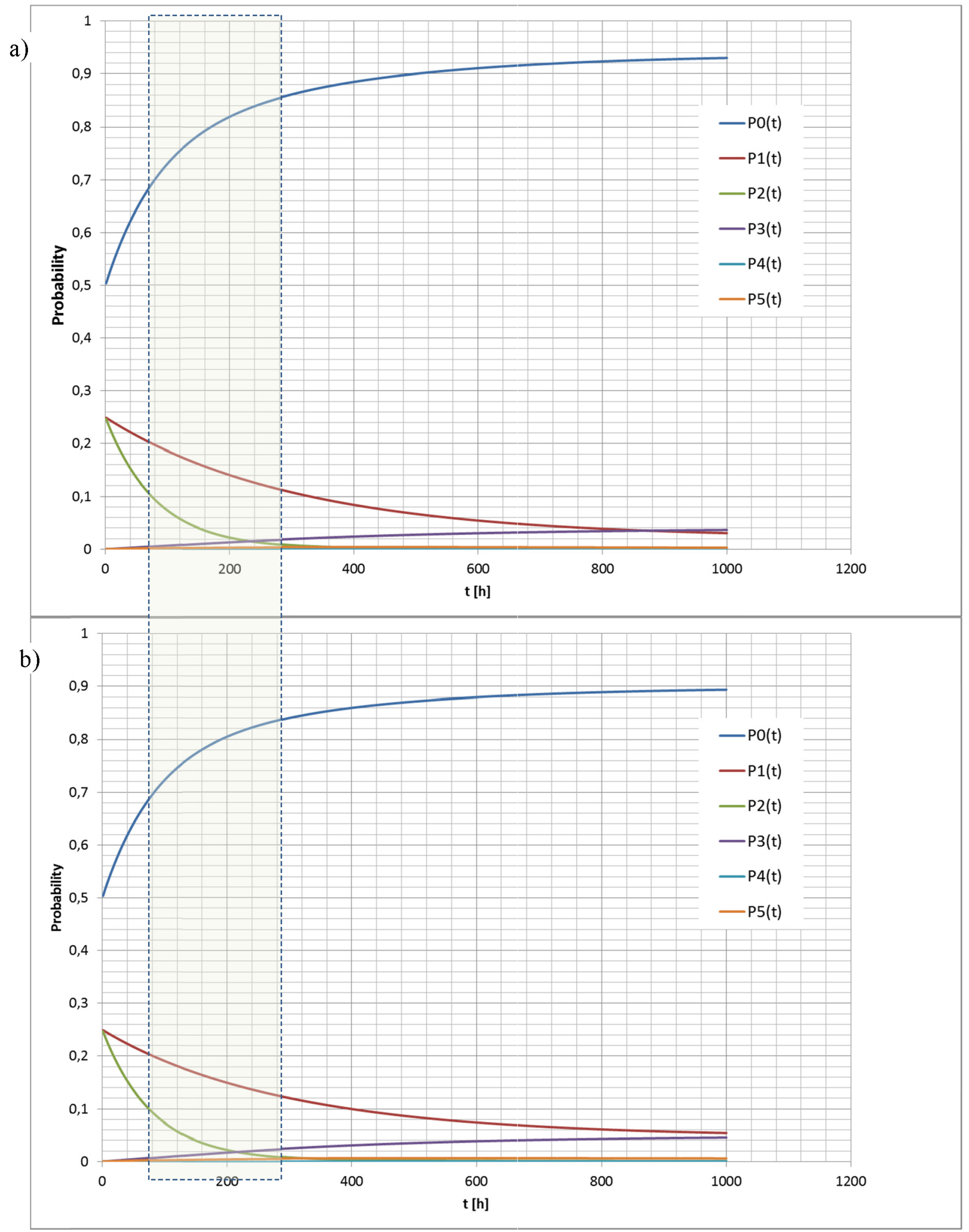

Fig. 5. The calculated current distribution for the initial distribution $p_{0}=P\left\{W^{\prime}(0)=s_{0}\right\}=0,5, p_{i}=P\left\{W^{\prime}(0)=s_{i}\right\}=0,25$ for $i=1,3 ; p_{i}=P\left\{W^{\prime}(0)=s_{i}\right\}=0$ for $i=$ 2,4,5; a) engine Wartsila RTA-96C, b) engine MAN B\&W L32/40 


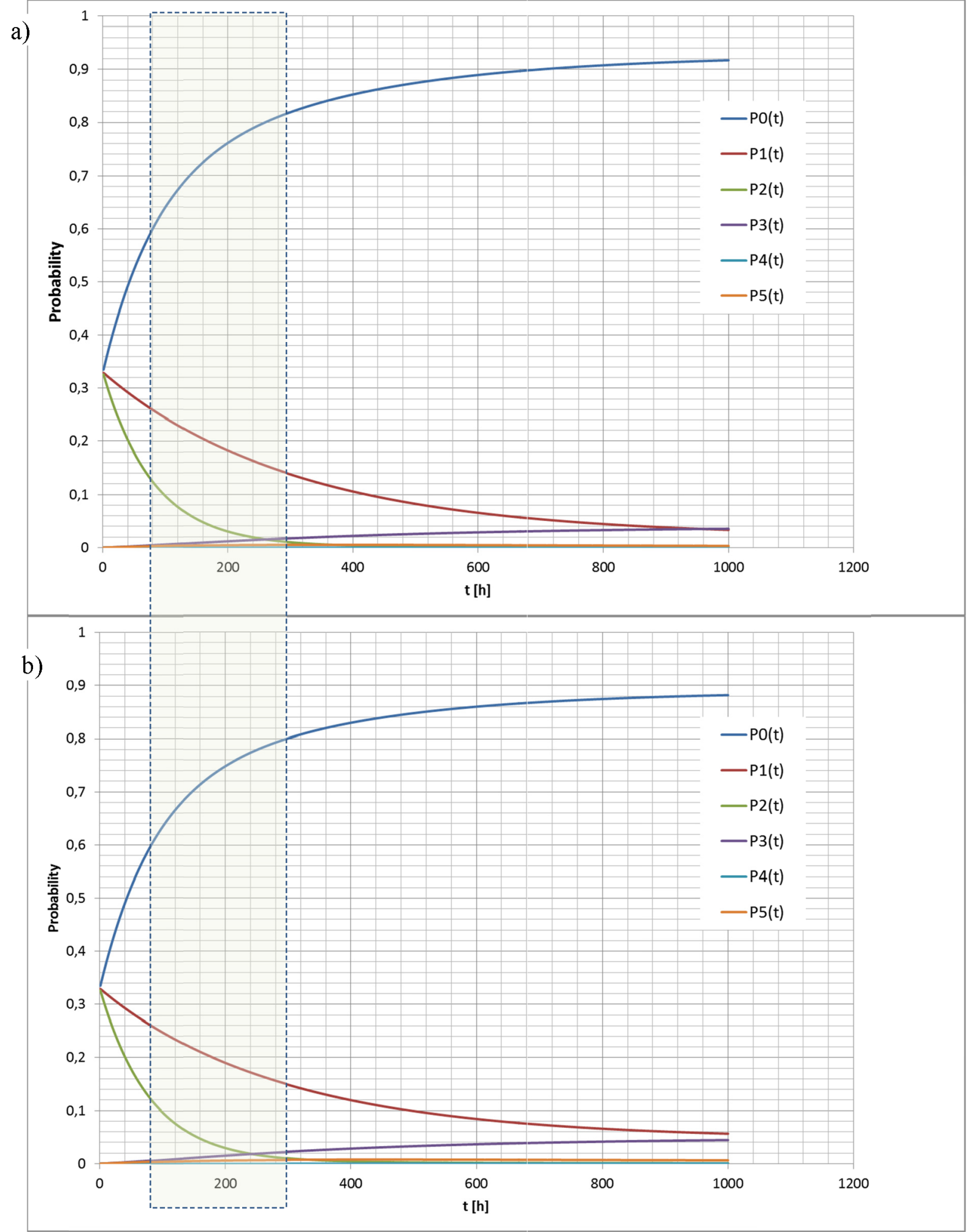

Fig. 6. The calculated current distribution for the initial distribution $p_{i}=P\left\{W^{\prime}(0)=s_{j}\right\}=0,33$, for $i=0,1,3 ; p_{i}=P\left\{W^{\prime}(0)=s_{i}\right\}=0$ for $i=2,4,5 ;$ a) engine Wartsila RTA-96C, b) engine MAN B\&W L32/40 
As can be seen in Figs. 4 to 6, from the point of view of decision making a crucial issue for tasks of medium time duration $(200-300 \mathrm{~h})$ is possibility to identify states $\mathrm{s}_{1}$ and $\mathrm{s}_{3}$, as the lack of this possibility can result in unjustified decisions, i.e. either overoptimistic (when the assumed initial distribution is $\mathrm{p}_{0}=\mathrm{P}\left\{\mathrm{W}^{\prime}(0)=\mathrm{s}_{0}\right\}=1, \mathrm{p}_{\mathrm{i}}=\mathrm{P}\left\{\mathrm{W}^{\prime}(0)=\mathrm{s}_{\mathrm{i}}\right\}=0$ for $i=1, \ldots, 5$ ), or excessively cautious (when the assumed initial distribution is $\mathrm{p}_{\mathrm{i}}=\mathrm{P}\left\{\mathrm{W}^{\prime}(0)=\mathrm{s}_{\mathrm{i}}\right\}=0,33$, for $\mathrm{i}=0,1,3$; $\mathrm{p}_{\mathrm{i}}=\mathrm{P}\left\{\mathrm{W}^{\prime}(0)=\mathrm{s}_{\mathrm{i}}\right\}=0$ for $\left.\mathrm{i}=2,4,5\right)$.

\section{CONCLUSIONS}

As the models of real engine operation processes, the semiMarkov processes seem to be more useful than the widely popularised Markov processes. This opinion mainly results from the fact that when analysing processes with continuous time parameter and finite set of states, the intervals of staying of the examined processes in particular states are random variables with arbitrary distributions. This fact makes it possible to take into account, in the developed models, physical aspects of main wear processes being the source of technical state changes. However, practical utilisation of the above models requires, among other features, sufficiently moderate complication level represented by the model, in the sense of a possible smallest number of defined state classes and a relatively simple, in the mathematical sense, functional matrix - $Q(t)$.

This condition is essential when estimating the current distribution $\mathrm{p}_{\mathrm{k}}(\mathrm{t})$ of process states. This distribution can be calculated based on the known initial distribution of the process and the function $\mathrm{p}_{\mathrm{ij}}(\mathrm{t})$. Calculating the probability $\mathrm{p}_{\mathrm{ij}}(\mathrm{t})$ consists in solving the second-order Voltera equation system in which the know quantities are the functions $\mathrm{Q}_{\mathrm{ij}}(\mathrm{t})$ being the elements of the functional matrix $\mathrm{Q}(\mathrm{t})$ of the process. When the number of process states is small and the functional matrix of this process is relatively simple, the system can be solved in the operator domain using the Laplace transform. On the other hand, when the number of states is large or its functional matrix (kernel of the process) is very complex, the equation system can only be solved numerically. This solution does not provide an answer to a question which is very important for operating practice, namely: how will the probabilities of states of the semi-Markov process change when $t$ is large.

It results from the theory of semi-Markov processes that in case of ergodic semi-Markov processes the above probabilities tend with time to precisely defined constant numbers $[3,4]$. These numbers bear the names of limiting probabilities of states, and the sequence of these numbers composes the limiting distribution of the process. The limiting distribution can be calculated much more easily than the current distribution, and it enables to define the readiness coefficient, of an engine for instance, and the income or cost per unit time of operation. These quantities, in turn, can be criterial functions when solving engine operation optimisation problems.

However, when the graph of state changes - passages is relatively complicated, a possibility appears to assess the searched probability values by developing the model of the process $\{\mathrm{W}(\mathrm{t})$ $: t \geq 0\}$ in the form of the Markov process - $\left\{W^{\prime}(t): t \in T\right\}$.
Such models represent some simplification of the semiMarkov models. The difference between the Markov process and the semi-Markov process is that in the former process the intervals in which the process stays unconditionally in particular states and the intervals of time duration of a given process state provided that then next state is one of the remaining states of this process are random variables with exponential distribution [1]. This situation limits the use of these processes, but in case of the above described difficulties in working out the semi-Markov model or when the analysed random variables have unknown distributions, the results obtained using the Markov process can be considered the first approximation.

The use of exponential distributions make it possible to obtain very simple relations constituting the distribution of the analysed process.

\section{REFERENCES}

1. Benjamin J.R., Cornell C.A.: Probability theory, mathematical statistics, and decision making theory for engineers (in Polish). WNT, Warszawa 1977.

2. Girtler J.: The semi-Markov model of the process of appearance of sea-going ship propulsion system ability and inability states in application to determining the reliability of these systems. Polish Maritime Research. Volume 20, Issue 4, Pages 18-24, 2013.

3. Girtler J.: The semi-Markov model of energy state changes of the main marine internal combustion engine and method for evaluating its operation during ship voyage. Polish Maritime Research. Volume 18, Issue 4, Pages 3642, 2011.

4. Grabski F.: Theory of semi-Markov processes of operation of technical objects (in Polish). Zeszyty Naukowe AMW, nr 75A, Gdynia 1982.

5. Piaseczny L.: Technology of repairs of marine internal combustion engines (in Polish). Wydawnictwo Morskie, Gdansk 1992.

6. Rudnicki J.: Preparing a collection of technical and energy states of engine piston-crankshaft systems taking place during engine operation (in Polish). Work done within the framework of the project finances by MNiSW. The research project entitled: „Decision making based control of the process of operation of piston-crankshaft systems in Diesel engines used as main propulsion of sea going vessels, making use of technical diagnostics and taking into account safety and marine environment protection. Gdansk 2010.

7. Rudnicki J.: Formulating requirements concerning operating properties of the diagnostic system for ship main engines, with particular attention focused on the 
technical state of their piston-crankshaft systems, adapted to control the process of operation of this type of engines in the aspect of ship safety and marine environment protection (in Polish). Work done within the framework of the project No. N N509 494638finances by MNiSW. The research project entitled: „Decision making based control of the process of operation of piston-crankshaft systems in Diesel engines used as main propulsion of sea going vessels, making use of technical diagnostics and taking into account safety and marine environment protection. Gdansk 2011.

8. Włodarski J.K.: Operating states of marine internal combustion engines (in Polish), WSM Gdynia 2001.

9. RTA 96CB Electronic Instruction \& Manual. Hunday Heavy Industries CO Ltd., Ulsan Korea 2010.

10. L32/40 Electronic Instruction \& Manual. Hunday Heavy Industries CO Ltd., Ulsan Korea 2010.

\section{CONTACT WITH THE AUTHOR}

Jacek Rudnicki

Gdańsk University of Technology 11/12 Narutowicza St. 80 - 233 Gdańsk

Poland 